\title{
Ab initio calculations of structural, elastic, electronic and thermodynamic properties of the cerium filled skutterudite $\mathrm{CeRu}_{4} \mathrm{P}_{12}$ under the effect of pressure
}

\author{
Mokhtar Berrahal ${ }^{1}$, Mohammed Ameri ${ }^{1,4 *}$, Y. Al-Douri ${ }^{2}$, U. HASHim$^{2}$,

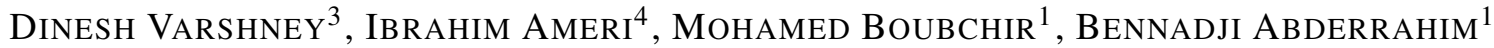 \\ ${ }^{1}$ Laboratory Physico-Chemistry of Advanced Materials, University of Djillali Liabes, BP 89, Sidi-Bel-Abbes, 22000, Algeria \\ ${ }^{2}$ Institute of Nano Electronic Engineering, University Malaysia Perlis, 01000 Kangar, Perlis, Malaysia \\ ${ }^{3}$ Materials Science Laboratory, School of Physics, Vigyan Bhavan, Devi Ahilya University, Khandwa Road Campus, \\ Indore 452001, India \\ ${ }^{4}$ Djillali Liabes University, Faculty of Exact Sciences, Department of Physics, PO Box 089, Sidi Bel Abbes, 22000, Algeria
}

The paper presents an investigation on crystalline, elastic and electronic structure in addition to the thermodynamic properties for a $\mathrm{CeRu}_{4} \mathrm{P}_{12}$ filled skutterudite device by using the full-potential linear muffin-tin orbital (FP-LMTO) method within the generalized gradient approximations (GGA) in the frame of density functional theory (DFT). For this purpose, the structural properties, such as the equilibrium lattice parameter, bulk modulus and pressure derivatives of the bulk modulus, were computed. By using the total energy variation as a function of strain we have determined the independent elastic constants and their pressure dependence. Additionally, the effect of pressure $\mathrm{P}$ and temperature $\mathrm{T}$ on the lattice parameters, bulk modulus, thermal expansion coefficient, Debye temperature and the heat capacity for $C e \mathrm{Ru}_{4} \mathrm{P}_{12}$ compound were investigated taking into consideration the quasi-harmonic Debye model.

Keywords: ab-initio calculations; GGA; density functional theory; $C e R u_{4} P_{12}$; elastic properties; thermal properties

(C) Wroclaw University of Technology.

\section{Introduction}

The current need for alternative energy technologies and materials to replace the depleting supplies of fossil fuels is becoming more and more urgent. Over the past 10 to 15 years, there have been significant advances in the scientific understanding as well as in the performance of thermoelectric (TE) materials $[1,2]$. The development and potential of bulk materials for TE applications include high-temperature materials, such as skutterudites, clathrates, half-Heusler alloys, and complex chalcogenides [3]. The chemical formula of a filled skutterudite is $\mathrm{R}_{2} \mathrm{M}_{8} \mathrm{X}_{24}$. The more common one is $\mathrm{RM}_{4} \mathrm{X}_{12}$ considering of the rhombohedral unit cell $(\mathrm{R}=$ rare earth, $\mathrm{M}=\mathrm{Fe}, \mathrm{Ru}$, or $\mathrm{Os}, \mathrm{X}=\mathrm{P}, \mathrm{As}$, or $\mathrm{Sb})$ [4]. In our study, $(\mathrm{Ce})$ refers to the lanthanide

\footnotetext{
*E-mail: lttnsameri@yahoo.fr
}

element $\mathrm{R},(\mathrm{Ru})$ to the transitional element $\mathrm{M}$ and $\mathrm{P}$ to $\mathrm{X}$ denote pnictogen.

Several features, such as heavy fermion behavior, superconductivity [5, 6], ferromagnetism, ant ferromagnetism, magnetic ordering [7], semiconductivity with small hybridization gap [8], nonFermi liquid behavior [9], and metal-insulator transition [10] have become the main interest for various theoretical and experimental investigations of this type of devices.

$\mathrm{CeRu}_{4} \mathrm{P}_{12}$ belongs to the filled skutterudite family. Accordingly, it crystallizes in a unique bodycentered-cubic and space structure $\operatorname{Im} 3$ [11] with two formula units $\left(\mathrm{RM}_{4} \mathrm{X}_{12}\right)$ per unit cell. There exist three unique atomic positions in the normalized unit cell. Yet, the positions of the remaining 31 atoms in the unit cell are determined by the symmetry operations, associated with the Im3 space group. One characteristic feature of 
skutterudite structure is that it contains two large empty cages or voids per unit cell, which can be partially or completely filled with filler atoms.

For the sake of completing the interesting experimental and theoretical investigations in progress, the proposed work sheds light on the physical properties of filled skutterudite device $\mathrm{CeRu}_{4} \mathrm{P}_{12}$, within the generalized gradient approximations (GGA) and in the frame of density functional theory (DFT).

We admit that limited data are available to describe the structural, elastic, electronic and thermodynamic properties of filled skutterudite $\mathrm{CeRu}_{4} \mathrm{P}_{12}$ compound. In an effort to understand the electronic properties and atomic bonding in filled skutterudites, band structure calculations have been performed.

The present paper is organized as follows: section 2 briefly discusses the computational method used in calculations, while section 3 is concerned with deduced results and their discussions. A comparison is also made with the available results. We end with conclusion in section 4 .

\section{Computational method}

The calculations presented in this work were performed through the full potential linear muffintin orbital (FP-LMTO) $[12,13]$ in the framework of DFT.

In this system, the space is divided into nonoverlapping muffin-tin (MT) spheres centered at the atomic sites separated by an interstitial region (IR). In the IR region, the Fourier series represents the basic functions. Inside MT spheres, the basic set is described by radial solutions of the Schrödinger equation particle (fixed energy) and their derivatives energy multiplied by spherical harmonics. To complete the energy eigenvalues convergence, wave functions in the interstitial region were increased in plane waves with an energy cutoff of 192.0213 Ry and a plane wave number equal to 71112. Muffin-tin spheres radii are considered as 3.704 a.u, 2.281 a.u and 2.156 a.u. for $\mathrm{Ce}, \mathrm{Ru}$ and $\mathrm{P}$, respectively. The wave functions of valence inside the spheres are expanded up to $\operatorname{lmax}=6$.
The exchange-correlation (XC) effects are treated with the GGA [14]. The k-integration over the Brillouin zone has been explored within the tetrahedron method [15] with a mesh of $6 \times 6 \times 6$ points.

\section{Results and discussion}

\subsection{Equilibrium lattice and bulk modulus}

The crystal structure of $\mathrm{CeRu}_{4} \mathrm{P}_{12}$ is shown in Fig. 1. The $\mathrm{Ce}, \mathrm{Ru}$ and $\mathrm{P}$ atoms are positioned, respectively, as follows: ( $\left(\begin{array}{lll}0 & 0 & 0\end{array}\right)\left(\begin{array}{lll}-1 / 4 & 1 / 4 & 1 / 4\end{array}\right)$, (1/4 -1/4 1/4), (1/4 1/4 -1/4) for $\mathrm{Ru}$ and $\mathrm{P}$ atoms located at $\left(\begin{array}{lll}0 & \mathrm{y} & \mathrm{z}\end{array}\right),\left(\begin{array}{llll}0 & \mathrm{y} & -\mathrm{z}\end{array}\right),\left(\begin{array}{lll}\mathrm{z} & 0 & \mathrm{y}\end{array}\right)$, $\left(\begin{array}{lll}-z & 0 & y\end{array}\right),\left(\begin{array}{lll}y & z & 0\end{array}\right),(y-z \quad 0),\left(\begin{array}{lll}0 & -y & -z\end{array}\right),\left(\begin{array}{lll}0 & -y & z\end{array}\right)$, $(-z \quad 0-y),(z \quad 0-y),(-y-z \quad 0),(-y$ z 0$)$. We performed the structural optimization by minimizing the total energy with respect to atomic positions $y$ and $\mathrm{z}$ and the lattice parameters.

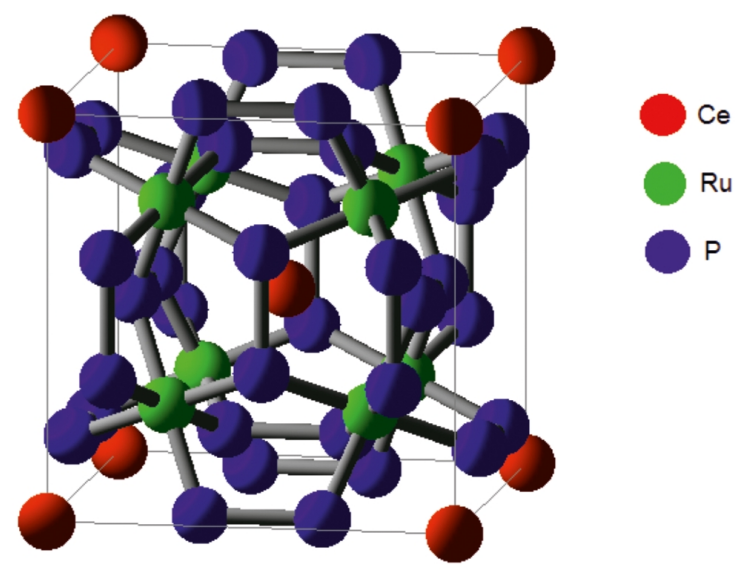

Fig. 1. Model of filled skutterudite.

While estimating the ground state properties of $\mathrm{CeRu}_{4} \mathrm{P}_{12}$, the total energies have been calculated for different volumes around the equilibrium cell volume. In Fig. 2, we present the variation of the total energy as a function of cell volume. The calculated total energy was fitted to Murnaghan's equation of state [16]. We determined: the lattice constant $\mathrm{a}_{0}$, the bulk modulus $\mathrm{B}_{0}$ and its pressure derivative B', y and $\mathrm{z}$, which are summarized in Table 1 together with available experimental and theoretical values [17-23]. The lattice constant of $\mathrm{CeRu}_{4} \mathrm{P}_{12}(8.0855 \AA)$ is significantly bigger than 
would be expected for trivalent $\mathrm{Ce}$ based on the values for $\mathrm{CeOs}_{4} \mathrm{P}_{12}(8.0626 \AA)$ [20] and $\mathrm{CeFe}_{4} \mathrm{P}_{12}$ (7.792 $\AA$ ) [24].

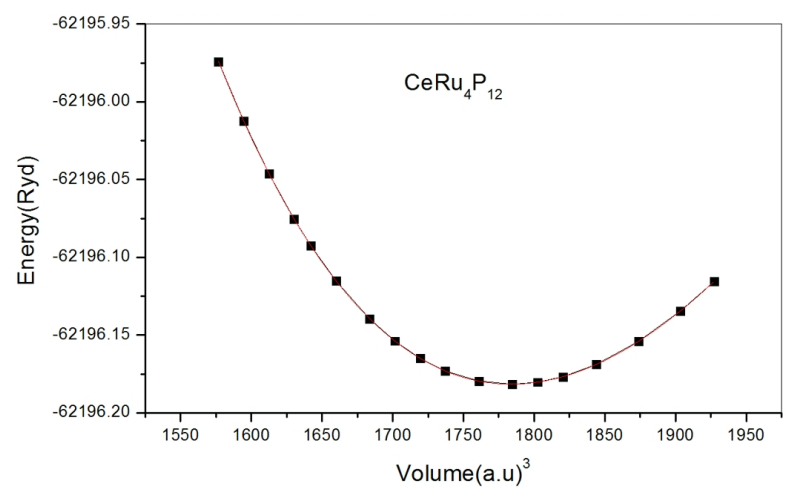

Fig. 2. Calculated total energies as a function of unit cell volume for $\mathrm{CeRu}_{4} \mathrm{P}_{12}$.

\subsection{Elastic properties}

The elastic constants of materials describe its response to an applied stress or, conversely, the stress required to maintain a given deformation. Both stress and strain have three tensile and three shear components, giving six components in total. The linear elastic constants form a $6 \times 6$ symmetric matrix, having 27 different components, such that $\sigma_{\mathrm{i}}=\mathrm{C}_{\mathrm{ij}} \cdot \varepsilon_{\mathrm{j}}$ for small stresses $\sigma$ and strains $\varepsilon$ [25]. Any symmetry present in the structure may make some of these components equal and others may be fixed at zero. Thus, a cubic crystal has only three different symmetry elements $\left(\mathrm{C}_{11}, \mathrm{C}_{12}\right.$ and $\mathrm{C}_{44}$ ), each of which represents three equal elastic constants $\left(\mathrm{C}_{11}=\mathrm{C}_{22}=\mathrm{C}_{33}, \mathrm{C}_{12}=\mathrm{C}_{23}=\mathrm{C}_{31}\right.$, $\mathrm{C}_{44}=\mathrm{C}_{55}=\mathrm{C}_{66}$ ). A single strain with non-zero first and fourth components can give stresses relating to all three of these coefficients, yielding a very efficient method for obtaining elastic constants for the cubic system. Thus, for the calculation of elastic constants $\mathrm{C}_{11}, \mathrm{C}_{12}$ and $\mathrm{C}_{44}$ we have used the Mehl method [26-29] of imposing the conservation of volume of a sample under the effect of pressure. To calculate the difference of elastic moduli, $\mathrm{C}_{11}-\mathrm{C}_{12}$, we apply the following orthorhombic strain tensor:

$$
\bar{\varepsilon}=\left[\begin{array}{lll}
\delta & 0 & 0 \\
0 & \delta & 0 \\
0 & 0 & \frac{1}{\left(1+\delta^{2}\right)}-1
\end{array}\right]
$$

where $\delta^{2}$ is the applied stress that varies between $\left(5 \times 10^{-4}\right.$ to $\left.3 \times 10^{-3}\right)$.

The application of this strain affects the total energy:

$E(\delta)=E(-\delta)=E(0)+6\left(C_{11}-C_{12}\right) V_{0} \delta^{2}+\mathrm{O}\left[\delta^{4}\right](2)$

where $E(0)$ is the energy of the system in the initial state (without stress), $V_{0}$ is the volume of unit cell. Moreover, for an isotropic cubic crystal, the bulk modulus is related to $\mathrm{C}_{\mathrm{ij}}$ constants according to equation $[30,31]$ :

$$
B=\left(C_{11}+2 C_{12}\right) / 3
$$

For determining the coefficient $\mathrm{C}_{44}$, the following monoclinic strain tensor is used:

$$
\bar{\varepsilon}=\left[\begin{array}{lll}
1 & \frac{\delta}{2} & 0 \\
\frac{\delta}{2} & 1 & 0 \\
0 & 0 & \frac{4}{\left(4-\delta^{2}\right)}
\end{array}\right]
$$

This transforms the total energy to:

$$
E(\delta)=E(-\delta)=E(0)+\frac{1}{2} C_{44} V_{0} \delta^{2}+\mathrm{O}\left[\delta^{4}\right]
$$

Fig. 3 represents the variation of the total energy, with respect to the square of the orthorhombic and monoclinic strains, used to determine $\mathrm{C}_{11}-\mathrm{C}_{12}$ and $\mathrm{C}_{44}$, respectively. Combining equations 2 and 3 , one can easily determine the two elastic constants $\mathrm{C}_{11}$ and $\mathrm{C}_{12}$, while the third elastic constant, in equation 5 is deduced by $\mathrm{C}_{44}$. From the elastic constants we obtain the anisotropy parameter $\mathrm{A}$ (for an isotropic crystal, $\mathrm{A}$ is equal to 1 , while another value greater or less than 1 means that it is an anisotropic crystal), Poisson's ratio $v$ characterizes the tension of a solid perpendicular to the direction of the force applied, the Young's modulus E measures the resistance of a solid to a change in its length and the shear modulus $G$ measures the resistance to movement of sliding planes in the interior of a solid with planes parallel to the latter, which is represented by the following equations:

$$
A=\frac{2 C_{44}}{C_{11}-C_{12}}
$$




$$
\begin{gathered}
v=\frac{3 B-E}{6 B} \\
E=\frac{9 B G}{3 B+G} \\
G=\frac{C_{11}-C_{12}+3 C_{44}}{5}
\end{gathered}
$$

where $\mathrm{B}$ is the bulk modulus given by equation 2 . The calculated elastic constants $\mathrm{C}_{\mathrm{ij}}$, the shear modulus G, the Young's modulus E, the Poisson's ratio $(v)$ and the anisotropic parameter A are summarized in Table 2. From these results, we find that the stability criteria $[32,33]: \mathrm{C}_{11}-\mathrm{C}_{12}>0$, $\mathrm{C}_{11}>0, \mathrm{C}_{44}>0,\left(\mathrm{C}_{11}+2 \mathrm{C}_{12}\right)>0$ and $\mathrm{C}_{12}$ $<\mathrm{B}<\mathrm{C}_{11}$, are satisfied for the studied skutterudites, and, therefore, it is elastically stable. From Table 1 and Table 2, it can be seen that the value of the bulk modulus B calculated from the elastic constants at $\mathrm{P}=0 \mathrm{GPa}$ has nearly the same value as that obtained from the fit points $E_{\text {tot }}$ (V) using the Murnaghan's equation of state of (EOS) [16]. In order to determine the nature of the material, Pugh [34] suggested a simple criterion $\mathrm{B} / \mathrm{G}$; if the value obtained of $\mathrm{B} / \mathrm{G}>1.75$ the ductility of the compound is provided. Otherwise, the material is brittle. The values of $\mathrm{B} / \mathrm{G}$ documented for $\mathrm{CeRu}_{4} \mathrm{P}_{12}$ in the Table 2 infer brittle character of this compound. The Poisson's ratio $v$ reflects information about the plasticity of materials. Its value for an ionic crystal is equal to 0.25 [35-37], and it ranges between -1 and $1 / 2$ for isotropic materials. For $\mathrm{CeRu}_{4} \mathrm{P}_{12}$, we deduced Poisson's ratio of about 0.032 .This essentially classifies $\mathrm{CeRu}_{4} \mathrm{P}_{12}$ as an isotropic material [38]. In Fig. 4, we present the pressure dependence of the elastic constants as well as the bulk modulus for $\mathrm{CeRu}_{4} \mathrm{P}_{12}$. It is clear that the elastic constants $\mathrm{C}_{11}$ and $\mathrm{C}_{44}$, increase with the pressure in a linear way but the elastic constant $\mathrm{C}_{12}$ decreases with the pressure.

\subsection{Electronic properties}

The band structure calculated for the equilibrium geometry of $\mathrm{CeRu}_{4} \mathrm{P}_{12}$ and various symmetry lines within the GGA scheme are presented in

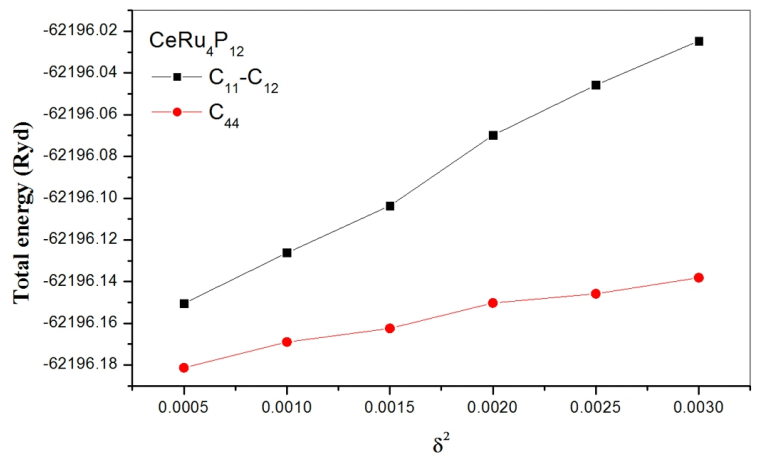

Fig. 3. The variation of the total energy with stress for a monoclinic and orthorhombic $\mathrm{CeRu}_{4} \mathrm{P}_{12}$.

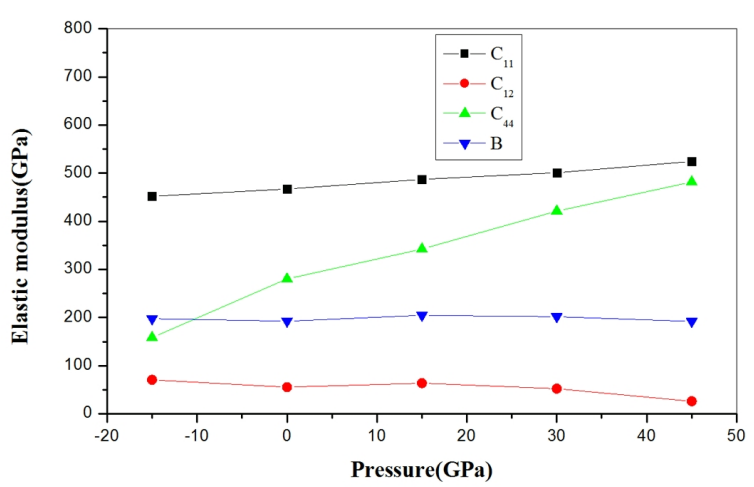

Fig. 4. Calculated pressure dependence of $C_{i j}$ and $B$ for $\mathrm{CeRu}_{4} \mathrm{P}_{12}$.

Fig. 5. In Table 3, the calculated values of band parameters associated with the experimental and theoretical results are illustrated [19, 24]. Fig. 6 displays the variation of some direct and indirect band gaps versus pressure. We have monitored the variation of the topological band structure under the hydrostatic pressure effect, in the range of -15 to $45 \mathrm{GPa}$ with a step of $15 \mathrm{GPa}$. The topology of the curves remains unchanged. However, the energy band gap increases along with increasing pressure. Predicting the valence band maximum at $\Gamma$ point and the conduction band minimum at $\mathrm{N}$ point results in an indirect band gap of material $(\Gamma-\mathrm{N})$. The value of this gap turns out to be $0.119 \mathrm{eV}$ when the pressure value is equal to $0 \mathrm{GPa}$ compared to a gap of $0.075 \mathrm{eV}$, estimated from electrical transport measurements of polycrystalline samples obtained by Shirotani et al. [17]. On the one hand, it is bigger than the gap of $\mathrm{CeOs}_{4} \mathrm{P}_{12}(0.036 \mathrm{eV})$ [17] and, 
Table 1. Lattice constant $\mathrm{a}_{0}$ (in $\AA$ ), pnicogen atom free internal parameters y and z, bulk modulus B (in GPa), its pressure derivative $\mathrm{B}^{\prime}$ and minimum energy of equilibrium $\mathrm{E}_{0}$ (in $\mathrm{Ryd}$ ) for $\mathrm{CeRu}_{4} \mathrm{P}_{12}$. Experimental data are quoted for comparison.

\begin{tabular}{ccccccc}
\hline $\mathrm{CeRu}_{4} \mathrm{P}_{12}$ & $\mathrm{a}_{0}$ & $\mathrm{y}$ & $\mathrm{Z}$ & $\mathrm{B}$ & $\mathrm{B}^{\prime}$ & $\mathrm{E}_{0}$ \\
\hline \hline Present & 8.0855 & 0.358 & 0.144 & 192.536 & 5.18136 & -62196.18154 \\
\hline Exp. & $8.0376[17]$ & - & - & - & - & - \\
& $8.0497[18]$ & - & - & $226 \pm 16[18]$ & $6 \pm 2[18]$ & - \\
\hline Other. calc. & $7.93[19]$ & $0.3456[19]$ & $0.145[19]$ & $240.52[19]$ & $5.21[19]$ & \\
\hline$\left(\mathrm{CeOs}_{4} \mathrm{P}_{12}\right)[20]$ & 8.0626 & - & - & - & - & - \\
$\left(\mathrm{CeFe}_{4} \mathrm{P}_{12}\right)[20]$ & 7.792 & - & - & - & - & - \\
$\left(\mathrm{CeOs}_{4} \mathrm{Sb}_{12}\right)[21]$ & 9.292 & 0.341 & 0.156 & 123 & 3.867 & -311370.9325 \\
$\left(\mathrm{Pre}_{4} \mathrm{P}_{12}\right)[22]$ & 7.6776 & 0.3525 & 0.151 & 186.7916 & 3.6965 & -236821.45838 \\
$\left(\mathrm{UFe}_{4} \mathrm{P}_{12}\right)[23]$ & 7.651 & 0.3503 & 0.1491 & 199.227 & 3.585 & \\
\hline
\end{tabular}

Table 2. Calculated elastic constant $\mathrm{C}_{11}, \mathrm{C}_{12}, \mathrm{C}_{44}$ (in GPa), bulk modulus (in GPa), Young and shear modulus $\mathrm{E}$, $\mathrm{G}$ (in GPa), Poisson's ratio $v$, and the anisotropic parameter A for $\mathrm{CeRu}_{4} \mathrm{P}_{12}$.

\begin{tabular}{cccccccccc}
\hline $\mathrm{P}$ & $\mathrm{C}_{11}$ & $\mathrm{C}_{12}$ & $\mathrm{C}_{44}$ & $\mathrm{~B}$ & $\mathrm{G}$ & $\mathrm{E}$ & $\mathrm{A}$ & $v$ & $\mathrm{~B} / \mathrm{G}$ \\
\hline \hline-15 & 451.73 & 70.45 & 158.46 & 197.54 & 188.42 & 428.90 & 0.83 & 0.138 & 1.044 \\
\hline 0 & 466.94 & 55.25 & 280.07 & 192.48 & 261.43 & 539.87 & 1.36 & 0.032 & 0.736 \\
Other. calc. & $384.21[19]$ & $60.34[19]$ & $228.61[19]$ & $201.93[19]$ & $473.34[19]$ & $1.41[19]$ & $0.1732[19]$ & & \\
\hline$\left(\mathrm{CeOs}_{4} \mathrm{Sb}_{12}\right)[21]$ & 245 & 62 & 63 & 123 & 74 & 186 & 0.39 & 0.25 & 1.65 \\
$\left(\mathrm{PrFe}_{4} \mathrm{P}_{12}\right)[22]$ & 437.557 & 61.4087 & 156.288 & 186.791 & 169.00246 & 389.53 & 0.931 & 0.152 & 1.10 \\
$\left(\mathrm{UFe}_{4} \mathrm{P}_{12}\right)[23]$ & 524.11 & 36.787 & 386.83 & 199.227 & 329.56 & 637.83 & 1.59 & -0.003 & 0.60 \\
\hline+15 & 486.87 & 63.49 & 342.14 & 204.62 & 299.65 & 604.08 & 1.61 & 0.007 & 0.682 \\
\hline+30 & 500.87 & 52.14 & 421.28 & 201.71 & 346.94 & 661.55 & 1.87 & -0.046 & 0.581 \\
\hline+45 & 524.22 & 25.8 & 481.66 & 191.94 & 384.84 & 692.02 & 1.93 & -0.100 & 0.498 \\
\hline
\end{tabular}

on the other hand, smaller than the gap of $\mathrm{CeFe}_{4} \mathrm{P}_{12}$ $(0.12 \mathrm{eV})[39]$ estimated from resistivity data.

Our results for the band structure show that $\mathrm{CeRu}_{4} \mathrm{P}_{12}$ compound is a narrow-gap semiconductor with an indirect energy band gap. It is found that this narrow-gap mainly comes from the hybridization of the $\mathrm{Ce} 4 \mathrm{f}$ states with the $\mathrm{Ru} \mathrm{d}$ and $\mathrm{P} \mathrm{p}$ orbitals which has already been indicated in the measurements of Kanai et al. [40].

\subsection{Thermodynamic properties}

While studying the thermodynamic properties of $\mathrm{CeRu}_{4} \mathrm{P}_{12}$, we have applied the quasi-harmonic Debye model as implemented in the Gibbs program [41]. The quasi-harmonic Debye model allows us to obtain all thermodynamic quantities from the calculated energy-volume points, in which the non-equilibrium Gibbs function $\mathrm{G}^{*}(\mathrm{~V} ; \mathrm{P} ; \mathrm{T})$ is expressed as follows:

$$
G^{*}(V ; P ; T)=E(V)+P V+A_{v i b}\left[\theta_{D}(V) ; T\right]
$$

Here, $\mathrm{E}(\mathrm{V})$ is the total energy per unit cell, PV corresponds to the constant hydrostatic pressure condition, $\theta_{\mathrm{D}}(\mathrm{V})$ is the Debye temperature, and $A_{v i b}$ is the vibrational Helmholtz free energy. According to the quasi-harmonic Debye model of phonon density of states, one can write $A_{\text {vib }}$ as [42]:

$$
\begin{aligned}
& A_{v i b}\left(\theta_{D}, T\right)= \\
& n K_{B} T\left[\frac{9 \theta_{D}}{8 T}+3 \ln \left(1-e^{-\theta_{D}} / T\right)-D\left(\frac{\theta_{D}}{T}\right)\right]
\end{aligned}
$$

Here, $\mathrm{n}$ is the number of atoms per formula unit, $K_{B}$ is Boltzmann's constant, $D\left(\theta_{D} / T\right)$ 

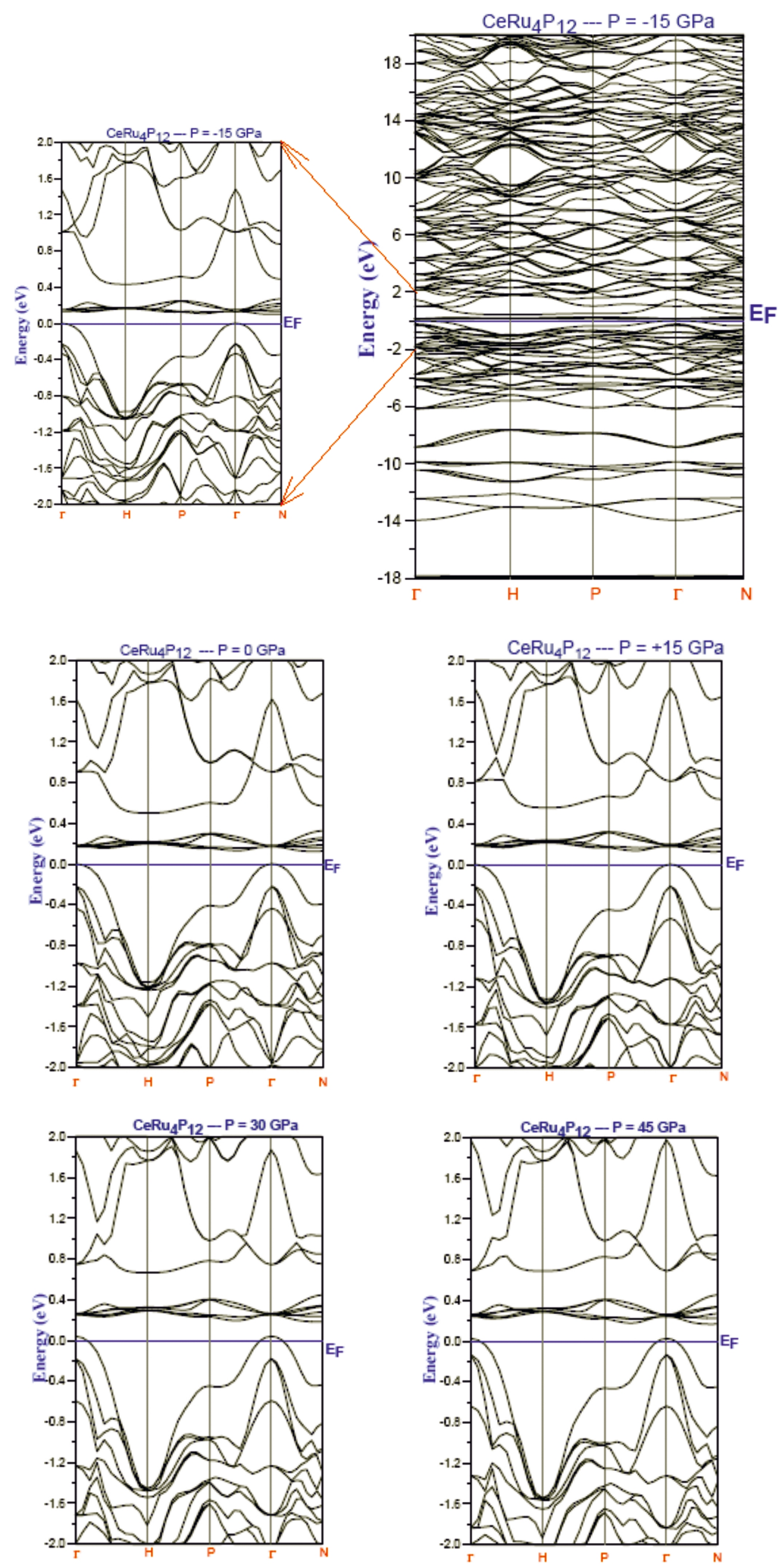

Fig. 5. The band structures for $\mathrm{CeRu}_{4} \mathrm{P}_{12}$ along the lines of symmetry of the Brillouin zone for a pressure calculated at $-15,0,15,30$ and $45 \mathrm{GPa}$, respectively. The position of the Fermi level is represented by a solid horizontal line. 
Table 3. Energy band gap $(\mathrm{eV})$ of $\mathrm{CeRu}_{4} \mathrm{P}_{12}$ along various symmetry lines versus pressure.

\begin{tabular}{ccccc}
\hline Pressure $(\mathrm{GPa})$ & $\Gamma-\Gamma$ & $\Gamma-\mathrm{H}$ & $\Gamma-\mathrm{P}$ & $\Gamma-\mathrm{N}$ \\
\hline \hline-15 & 0.12273 & 0.15795 & 0.12214 & 0.09566 \\
0 & 0.16075 & 0.19520 & 0.15214 & 0.11985 \\
+15 & 0.17584 & 0.21530 & 0.16595 & 0.12508 \\
+30 & 0.20565 & 0.25216 & 0.19383 & 0.14399 \\
+45 & 0.23012 & 0.27349 & 0.20854 & 0.14905 \\
Other calc. & - & - & - & $0.086[24]$ \\
LSDA calc. & $0.345[19]$ & $0.378[19]$ & $0.329[19]$ & $0.295[19]$ \\
\hline
\end{tabular}

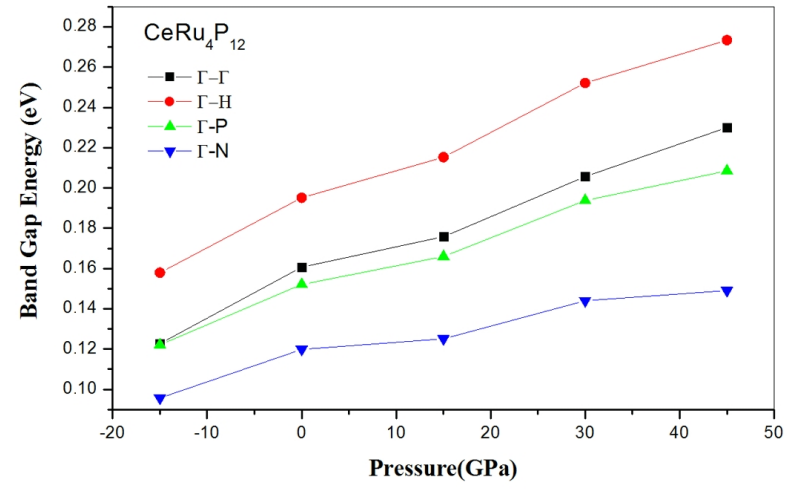

Fig. 6. Calculated pressure dependence of band gap energies for $\mathrm{CeRu}_{4} \mathrm{P}_{12}$.

represents the Debye integral. For an isotropic solid, $\theta_{\mathrm{D}}$ is expressed as $[41,43]$ :

$$
\theta_{D}=\frac{\hbar}{K_{B}\left(\left[6 \pi^{2} n V^{1 / 2}\right)-1 / 3 f(\sigma) \sqrt{\frac{B_{S}}{M}}\right.}
$$

Here, $\mathrm{M}$ is the molecular mass per unit cell and $\mathrm{B}_{\mathrm{S}}$ is the adiabatic bulk modulus measuring the compressibility of crystal, which is approximated by static compressibility as [44]:

$$
B_{S} \cong B(V)=V \frac{d^{2} E(V)}{d V^{2}}
$$

Details of quantities $f(\sigma)$ and $B_{S}$ are given in $[45,47]$. Therefore, the non-equilibrium Gibbs function $\mathrm{G}^{*}$ is a function of $(\mathrm{V} ; \mathrm{P} ; \mathrm{T})$ and is minimized with respect to volume $\mathrm{V}$ :

$$
\left[\frac{\partial G(V, P, T)}{\partial V}\right]_{P, T}=0
$$

By solving equation 13, we get the thermal equation (EOS) V (P, T). Heat capacity at a constant volume $C_{V}$ and thermal expansion coefficient $\alpha$ are given by [48]:

$$
\begin{gathered}
C_{V}=3 n K_{B}\left[4 D\left(\frac{\theta_{D}}{T}\right)-\frac{\left(\frac{3 \theta_{D}}{T}\right)}{e^{\theta_{D}} T-1}\right] \\
\alpha=\frac{\gamma C_{V}}{B_{T} T}
\end{gathered}
$$

Here, $\gamma$ is the Grüneisen parameter, which is defined as:

$$
\gamma=-\left(d \operatorname{Ln}\left(\theta_{\downarrow} D(V)\right) / d \operatorname{Ln} V\right.
$$

Through the quasi-harmonic Debye model, it is possible to calculate the thermodynamic quantities of $\mathrm{CeRu}_{4} \mathrm{P}_{12}$ device at arbitrary temperature from the calculated $\mathrm{E}-\mathrm{V}$ data at $\mathrm{T}=0$ and $\mathrm{P}=0$.

Fig. 7 shows the bulk modulus variation versus temperature at a given pressure.

One can notice that the bulk modulus is nearly constant from 0 to $300 \mathrm{~K}$ and decreases linearly with increasing temperature for $\mathrm{T}>300 \mathrm{~K}$. The compressibility increases with increasing temperature at a given pressure and decreases with pressure at a given temperature.

These results are caused by the fact that the effect of increasing pressure on the material is the same as that of the decreasing temperature. At $300 \mathrm{~K}$ and zero pressure, $\mathrm{B}=189.92 \mathrm{GPa}$.

The knowledge of the heat capacity of a substance provides essential insight into its vibrational 


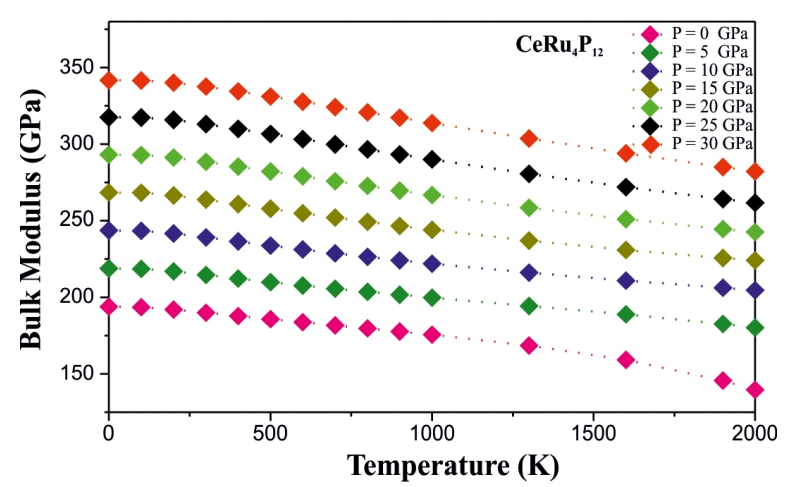

Fig. 7. The variation of the bulk modulus as a function of temperature at different pressures for $\mathrm{CeRu}_{4} \mathrm{P}_{12}$.

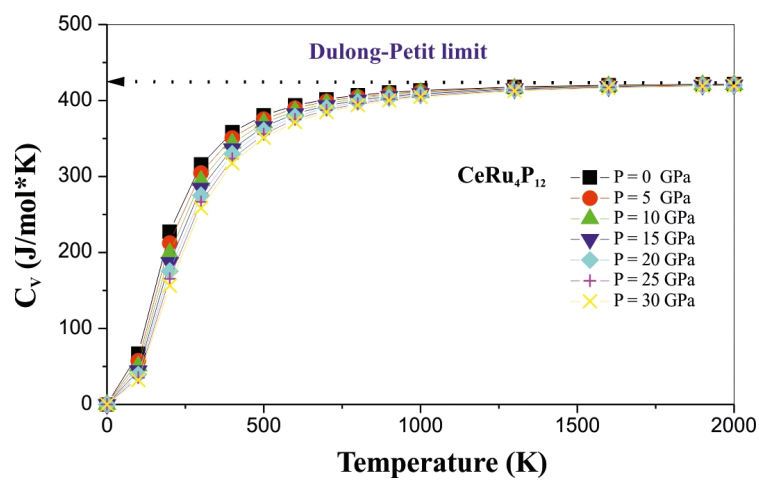

Fig. 8. The variation of the heat capacity $\mathrm{C}_{\mathrm{V}}$ as a function of temperature at different pressures of $\mathrm{CeRu}_{4} \mathrm{P}_{12}$.

properties and is also mandatory for many applications, so the variation of the heat capacity at constant volume $\mathrm{C}_{\mathrm{V}}$ versus temperature at $0,5,10$, 15, 20, 25 and $30 \mathrm{GPa}$ pressures for $\mathrm{CeRu}_{4} \mathrm{P}_{12}$ is shown in Fig. 8. It is worth mentioning that $\mathrm{C}_{\mathrm{V}}$ curve shows a sharp increase up to $1000 \mathrm{~K}$, and then increases slowly in the high temperature. At high temperature $\mathrm{C}_{\mathrm{V}}$ is close to a constant value of $424.91 \mathrm{~J} \cdot \mathrm{mol}^{-1} \cdot \mathrm{K}^{-1}$, which is the socalled Dulong-Petit limit [49], common to all solids at high temperature.

In view of Fig. 8, it is clear that when $\mathrm{T}<1000 \mathrm{~K}$, the heat capacity $\mathrm{C}_{\mathrm{V}}$ depends on both temperature and pressure. $\left(\mathrm{C}_{\mathrm{V}}\right.$ is proportional to temperature [50]).

On the other hand, we have studied the effect of temperature and pressure on the behavior of the

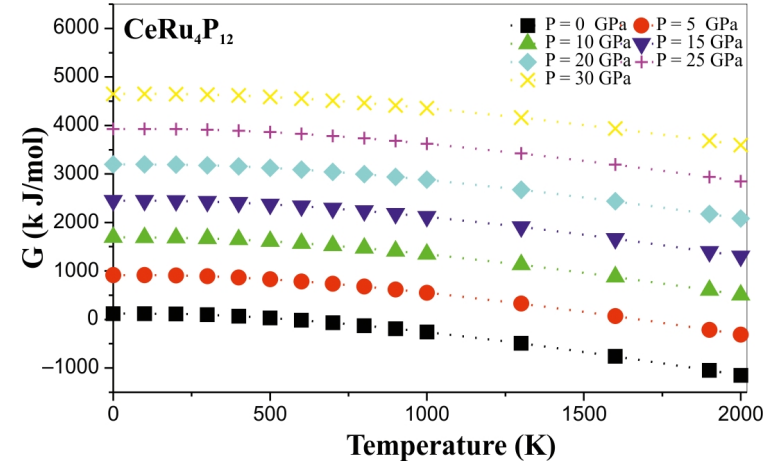

Fig. 9. The variation of the Gibbs energy as a function of temperature at different pressures of $\mathrm{CeRu}_{4} \mathrm{P}_{12}$.

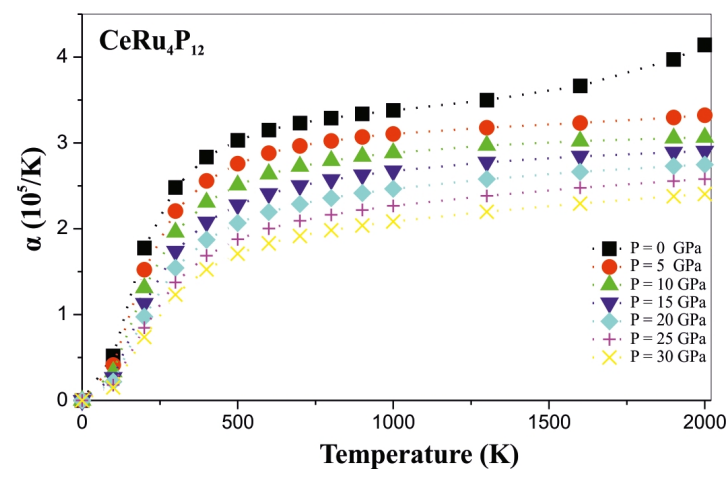

Fig. 10. The variation of the thermal expansion coefficient $\alpha$ as a function of temperature at different pressures of $\mathrm{CeRu}_{4} \mathrm{P}_{12}$.

variation of Gibbs energy in the temperature range of 0 to $2000 \mathrm{~K}$ at various pressures ( 0 to $30 \mathrm{GPa}$ ) as shown in Fig. 9. This factor is nearly constant from 0 to $600 \mathrm{~K}$ and decreases linearly with increasing temperature.

Fig. 10 presents the effect of temperature on the thermal expansion coefficient $(\alpha)$. It is shown that the thermal expansion coefficient $(\alpha)$ increases when temperature increases. At a given pressure, the thermal coefficient $\alpha$ increases sharply with increasing temperature up to $600 \mathrm{~K}$. Above this temperature, $\alpha$ gradually displays a linearly increasing trend with enhanced temperature.

The Debye temperature $\left(\theta_{\mathrm{D}}\right)$ is an significant parameter, characteristic of the thermal properties of solids. It is used to distinguish between the high and low temperature regions in the solids. 
The dependence of the Debye temperature $\theta_{\mathrm{D}}$ as a function of temperature and pressure is shown in Fig. 11. It is noticed that $\theta_{\mathrm{D}}$ decreases with enhanced temperature or, in other words, the resistance to deformation by a stress suppresses. A reduced $\theta_{\mathrm{D}}$ infers the thermal softening of the rare earth filled skutterudite lattice at different pressures. In view of this figure, it seen that $\theta_{\mathrm{D}}$ is nearly constant from 0 to $400 \mathrm{~K}$ and then decreases linearly with increasing temperature. At fixed temperature, the Debye temperature increases with the enhancement of pressure. From Fig. 11, it can be deduced the value of Debye temperature at zero pressure and zero temperature which is found to be $758.36 \mathrm{~K}$.

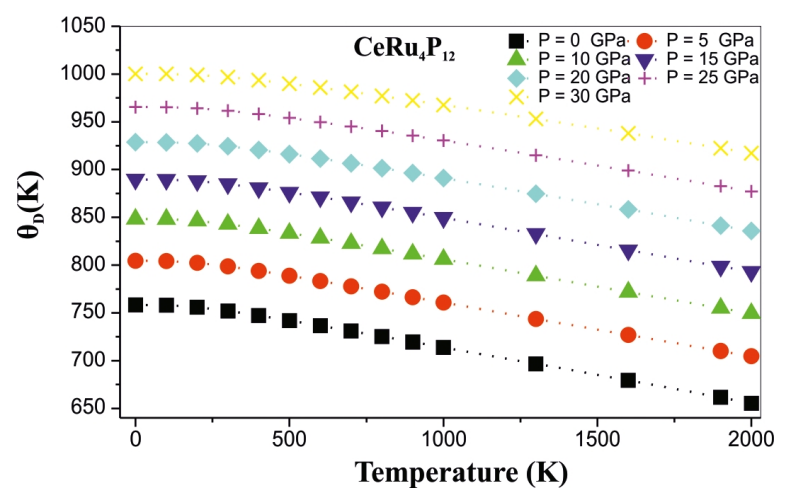

Fig. 11. The variation of the Debye temperature as a function of temperature at different pressures for $\mathrm{CeRu}_{4} \mathrm{P}_{12}$.

Fig. 12 shows the pressure and temperature dependence of the relative volume $\mathrm{V}$ for $\mathrm{CeRu}_{4} \mathrm{P}_{12}$. The relative volume $\mathrm{V}$ increases with increasing temperature but the rate is more significant for the temperature above $400 \mathrm{~K}$. On the other hand, at a given temperature, the relative volume $\mathrm{V}$ decreases when the pressure $P$ increases. The effect of increasing temperature on volume is just the same as decreasing pressure.

\section{Conclusion}

In summary, this work contributes to the structural, electronic and elastic properties of Ce-based filled skutterudite compound $\mathrm{CeRu}_{4} \mathrm{P}_{12}$ studied by the FP-LMTO method within the GGA in the frame

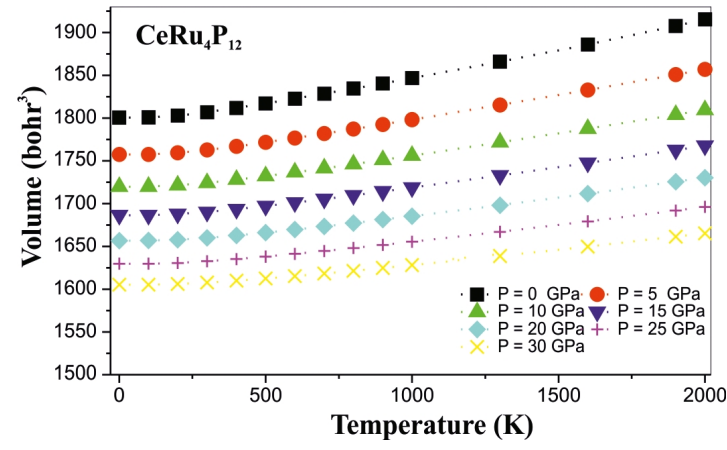

Fig. 12. Pressure and temperature dependence of the relative volume $\mathrm{V}$ for $\mathrm{CeRu}_{4} \mathrm{P}_{12}$.

of DFT. The deduced results are in good agreement with the experimental data found in the literature. We gave a prediction of the Debye temperature $\theta_{\mathrm{D}}$, shear modulus $\mathrm{G}$, Young's modulus $\mathrm{E}$, Poisson's ratio $v$ and the anisotropy parameter A for Ce-based filled skutterudite $\mathrm{CeRu}_{4} \mathrm{P}_{12}$. Furthermore, following the quasi-harmonic Debye model, the dependences of the volume, bulk modulus, heat capacities and Debye temperature on temperature and pressure were obtained successfully. Energy bands indicate that $\mathrm{CeRu}_{4} \mathrm{P}_{12}$ is a semiconductor with an indirect band gap. A very flat band along the symmetry axis $\Gamma-\mathrm{N}$ was determined in the range of $0.119 \mathrm{eV}$ at the pressure equal to $0 \mathrm{GPa}$.

\section{Acknowledgements}

Y. A. would like to acknowlegde the University Malaysia Perlis for Grant No. 9007-00111 and the TWAS-Italy for the full support of his visit to the JUST-Jordan under the TWASUNESCO Associateship.

\section{References}

[1] Heremans J., NanometerScale Thermoelectric Materials, in: BHUSHAN B. (Ed.), Springer Handbook on Nanotechnology, Springer, $2^{\text {nd }}$ ed, Heidelberg, 2007, p. 345.

[2] He J., TRITt T.M., ThermaltoElectrical Energy Conversion from the Nanotechnology Perspective, in: JAVIER G.M. (Ed.), Nanotechnology for the Energy Challenge, Wiley-VCH, Weinheim, 2010, p. 47.

[3] Nolas G.S., Poon S.J., Kanatzidis M., MRS Bull., 31 (2006), 199.

[4] Sales B.C., Handbook on the Physics and Chemistry of Rare Earths, Elsevier, Amsterdam, 2003.

[5] Maple M.B., Ho P.C., ZapF V.S., Frederick N.A., BAuERE D., Yuhasz W.M., WoOdWARd F.M., Lynn J.W., J. Phys. Soc. Jpn., 71 (2002), 23. 
[6] Bauer E.D., Frederick N.A., Ho P.C., ZAPF V.S., Maple M.B., Phys. Rev. B, 65 (2002), 100506.

[7] Danebrock M.E., Evers C.B.H., Jeitschko W., J. Phys. Chem. Solids, 57 (1996), 381.

[8] Meisner G.P., TorikachVili M.S., Yang K.N., MAPle M.B., Guertin R.P., J. Appl. Phys., 57 (1985), 3037.

[9] Takeda N., Ishikawa M., Physica B, 259 - 261 (1999), 92

[10] Sekine C., Uchiumi T., Shirotani I., Yagi T., Phys. Rev. Lett., 79 (1997), 3218.

[11] Meisner G.P., TorikachVili M.S., YAng K.N., Maple M.B., Guertin R.P., J. Appl. Phys., 57(1985), 3073.

[12] Nordström L., Singh D.J., Phys. Rev. B, 53 (1996), 1103.

[13] Savrasov S.Y., Phys. Rev. B, 54 (1996), 16470.

[14] Perdew J.P., Ruzsinszky A., Csonka G.I., VyDROV O.A., Scuseria G.E., Constantin L.A., Zhou X., Burke K., Phys. Rev. Lett., 100 (2008), 136406.

[15] Perdew J.P., Phys. Rev. B, 33 (1986), 8822.

[16] Murnaghan F.D., Proc. N.A.S., 30 (1944), 244.

[17] Shirotani I., Uchiumi T., Sekine C., Hiro M., KIMURA S., J. Solid State Chem., 142 (1999), 146.

[18] Shirotani I., Noro T., Hayashi J., Sekine C., Giri R., Kikegawa T., J. Phys. Condens. Matter, 16 (2004), 1.

[19] Benalia S., Hachemaoui M., Rached D., J. Phys. Chem. Solids, 70 (2009), 622.

[20] Jeitschko W., Braun D.J., Acta Cryst. B, 33 (1977), 3401.

[21] Ameri M., Boudia K., Khenata R., Bouhafs B., Rais A., Bin OMran S., Abidri B., Al-Douri Y., Mat. Sci. Semicon. Proc., 16 (2013), 1508.

[22] Ameri M., Abdelmounaim B., Sebane M., Khenata R., Varshney D., Bouhafs B., AMeri I., Mol. Simulat., 40 (11) (2014), 1.

[23] Ameri M., Slamani A., Abidri B., Ameri I., AlDouri Y., Bouhafs B., VArshney D., Adjadj A., Louahala N., Mat. Sci. Semicon. Proc., 27 (2014), 368.

[24] Sato H., Sugawara H., Aoki Y., Harima H., Handbook of Magnetic Materials, Elsevier, 2009.

[25] Ashcroft N.W., Mermin D., Solid State Physics, Saunders College, Philadelphia, 1976.

[26] Mehl M.J., Osburn J.E., Papaconstantopoulos D.A., KleIn B.M., Phys. Rev. B, 41 (1990), 10311.

[27] Mehl M.J., Klein B.M., Papaconstantopoulos D.A., First-Principles Calculation of Elastic Properties, in: West-Brook J.H., Fleisher R.L. (Eds.), Principles Intermetallic Compounds, Wiley, New York, 1995.
[28] Benalia S., Ameri M., Rached D., Khenata R., Rabah M., Bouhemadou A., Comput. Mat. Sci., 43 (2008), 1022.

[29] Rached H., Rached D., Khenata R., Reshak A.H., Rabah M., Phys. Status Solidi B, 246 (2009), 1580 .

[30] Schreiber E., Anderson O.L., Soga N., Elastic Constants and their Measurement, McGraw-Hill, New York, 1973.

[31] Nakanishi Y., Yamaguchi T., Hazama H., Goto T., Matsuda T.D., Sugawara H., Sato H., Yoshizawa M., J. Phys. Soc. Jpn., 71 (2002), 249.

[32] Born M., Math. Proc. Cambridge, 36 (1940), 160.

[33] Born M., Huang K., Dynamical Theory of Crystal Lattices, Clarendon Press, Oxford, 1956.

[34] Pugh S.F., Philos. Mag., 45 (1954), 823.

[35] Ledbetter M.H., Elastic Properties, in: Reed R.P., Clark A.F. (Eds.), Materials at Low Temperatures, American Society for Metals, Ohio, 1983, p. 1.

[36] Brazhkin V.V., Lyapin A.G., Hemley R.J., Philos. Mag., 82 (2002), 231

[37] Haines J., Leger J.M., Bocquillon G., Annu. Rev. Mater. Sci., 31 (2001), 1.

[38] GerceK H., Int. J. Rock Mech. Min., 44 (1) (2007), 1.

[39] Sato H., Abe Y., OKada H., Matsuda T., SugAWAra H., Aoki Y., Phys. Rev. B, 62 (2000), 15125.

[40] Kanai K., Takeda N., Nozawa S., Yokoya T., Ishikawa M., Shin S., Phys. Rev. B, 65 (2002), 041105(R)

[41] Blanco M.A., Francisco E., Luańa V., Comput. Phys. Commun., 158 (2004), 57.

[42] Blanco M.A., Martin Pendas A., Francisco E., Recio J.M., Franco R., J. Mol. Struct. Theochem, 368 (1996), 245.

[43] Florez M., Recio J.M., Francisco E., Blanco M.A., Martin Pendas A., Phys. Rev. B, 66 (2002), 144112.

[44] Fahy S., Chang K.J., Louis S.G., Cohen M.L., Phys. Rev B, 35 (1989), 7840.

[45] Francisco E., Recio J.M., Blanco M.A., Martin Pendas A., J. Phys. Chem., 102 (1998), 1595.

[46] Francisco E., Blanco M.A., Sanjurjo G., Phys. Rev. B, 63 (2001), 094107.

[47] POIRIER J. P., Introduction to the Physics of the Earth's Interior, Cambridge University Press, Oxford, 2000.

[48] Hill R., P. Roy. Soc. A-Math. Phy., 65 (1952), 349.

[49] Petit A.T., Dulong P.L., Annu. Rev. Phys. Chem., 10 (1819), 395.

[50] DeBYe P., Ann. Phys.-New York, 39 (1912), 789.

Received 2014-10-04 Accepted 2015-10-09 